Running head: Suicide and Associated Vulnerability Indicators in Adult Missing Persons: 1 Implications for the Police Risk Assessment

\title{
Suicide and Associated Vulnerability Indicators in Adult Missing Persons: Implications for the Police Risk Assessment
}

Hannah Yong and Calli.Tzani-Pepelasis

\begin{abstract}
Purpose: This research examined the relationship between adult missing persons and suicide, considering a number of possible vulnerability indicators/characteristics of this group of missing persons. Implications for missing person investigations were also explored, particularly for the risk assessment process.
\end{abstract}

Methodology: Data was extracted for ninety-three $(\mathrm{N}=93)$ missing persons cases from one English police force, over a four-year period. These individuals were found dead suspected of suicide.

Findings: The findings illustrate a number of vulnerability indicators/characteristics of missing persons who complete suicide. In relation to the initial risk assessment level applied to the missing person report, two vulnerability indicators; a risk of suicide and the presence of a suicide note had an effect on predicting a higher risk assessment level.

Limitations: Future research, in order to overcome the present study's limitations, should attempt to collect data from more than one police force in order to increase the sample size. In addition to this, it would be beneficial to use a sample of missing persons who are found safe and well as a 
Suicide and Associated Vulnerability Indicators in Adult Missing Persons

comparative sample to have a better chance in understanding the examined relationship and whether the vulnerability indicators/characteristics are indicative of suicide risk.

Practical implications: The findings of this study have practical implications for the risk assessment process and are a step forward in providing empirical evidence applicable to identifying missing persons most at risk of suicide.

Social implications: This research has helped to build upon and corroborate existing knowledge of missing persons who complete suicide.

Originality: This study provides new empirical evidence on suicide in adult missing persons. The findings demonstrate the subjective and variable nature of the risk assessment process and highlight potential implications on missing person investigations.

Key words: Missing persons; Suicide; Vulnerability indicators; 


\section{Introduction}

Reports of missing persons have increased year on year, with over 337,000 reports of missing and absent persons received by police forces within England and Wales between 2015 and 2016, equating to over 240,000 missing and absent incidents (UK Missing Persons Bureau, 2017). The National Police Chiefs' Council (NPCC), formerly the Association of Chief Police Officers (ACPO) defines a missing person as 'anyone whose whereabouts cannot be established, where the circumstances are out of character or the context suggests the person may be subject of crime or at risk of harm to themselves or another' (ACPO, 2013, p.5) ${ }^{1}$. Further to this definition of missing persons, a category of absent persons has been defined as 'a person not at a place where they are expected or required to be and there is no apparent risk' (ACPO, 2015, p.1).

When considering the number of missing person incidents received by the police, the demand of these investigations upon police resources is significant. The time spent on a missing person investigation is considered to be greater than time absorbed on an investigation of criminal damage or assault (Shalev Greene \& Pakes, 2013), and can quite often involve a multitude of resources to be deployed, such as specialist search officers, family liaison officers, and search helicopter support. On receipt of a missing person report, it is graded absent, low, medium or high, with a high-risk investigation requiring 'an immediate deployment of police resources' and medium risk requiring 'an active and measured response' (College of Policing, 2016). It is estimated that the cost of a missing person investigation categorised as medium risk, over a medium time period costs between $£ 1,325$ and $£ 2,415$ (Shalev Greene \& Pakes, 2013). Given that medium risk cases account for 76 per cent of all missing incidents within England and Wales, it is anticipated that the financial cost of medium risk missing person investigations alone is $£ 244 \mathrm{~m}-£ 445 \mathrm{~m}$ per year (UK Missing Persons Bureau, 2017).

\footnotetext{
${ }^{1}$ This definition changed in 2017 , however was valid at the time of data collection.
} 
Suicide and Associated Vulnerability Indicators in Adult Missing Persons

Of all persons that go missing, approximately 40 per cent are classified as adults over the age of 18. Whilst there is a variety of research concerning missing children, it is acknowledged that disproportionately a very limited amount of research exists regarding adult missing persons (Bonny, Almond, \& Woolnough, 2016; Foy, 2016). For all missing person cases in England and Wales between 2015 - 2016, less than one per cent were found deceased (UK Missing Persons Bureau, 2017). Newiss (2006) similarly reported 0.6 per cent of missing person incidents cancelled by the police subsequently resulted a fatal outcome, with suicide identified as a primary cause of death of missing persons within the UK (Newiss, 2011).

\subsection{Suicide and Associated Risk Factors}

Figures in 2016 for the UK show that 5965 deaths were recorded as suicide, correlating to 10.4 suicide deaths per 100,000 population. Of these deaths, males were approximately three times more likely to take their own life than females. The highest number of age-specific suicides was identified for persons aged 40 to 44 years, whereby the rate of suicide deaths stood at 15.3 per 100,000 population (ONS, 2017). Suicide is defined as 'all deaths from intentional self-harm for persons aged 10 and over, and deaths where the intent was undetermined for those aged 15 and over' (ONS, 2017, p.3).

Several research studies have considered the presence and frequency of suicide ideation to suicidal acts (Turecki \& Brent, 2016; Bebbington et al., 2010; Borges et al., 2010). Suicide ideation itself encompasses thoughts to take one's life, with active suicide ideation including plans or a method of how suicide might be accomplished (Turecki \& Brent, 2016). Various projects have studied the associated risk factors and reported that, suicidal thinking, mental health illness (Borges et al., 2010; Bebbington et al., 2010), previous suicide attempts (Borges et al., 2010; Hawton et al., 2015; Bergen et al., 2012; Carroll et al., 2016; Runeson, Tidemalm, Dahlin, Lichtenstein, \& Langstrom, 2010), episodes of self-cutting (Bergen et al., 2012), depression (Hawton, Casanas i Comabella, Haw \& Saunders, 2013; Harwood, Hawton, Hope \& Jacoby, 2001) particularly in 
correlation with old age (ONS, 2017), misuse of alcohol and drugs (Hawton et al., 2013; Carretta Burgess \& Welner, 2015; Darke, Torok, Crim, Kaye \& Ross, 2010), and adverse life events (Bagge, Glenn, \& Lee, 2013; Cooper, Appleby, \& Amos, 2002; Cavanagh, Owens, \& Johnstone, 1999) such as being investigated for a child sexual abuse and exploitation (CSAE) offence (Hoffer, Shelton, Behnke, \& Erdberg, 2010), increase the risks of suicide attempts and success. Specifically for the latter, the risk of suicide to individuals released from police custody, in particular those suspected of being involved in CSAE offences, is highlighted within Authorised Professional Practice (APP) ${ }^{2}$ (College of Policing, 2018). Finally, true suicide figures may be underestimated, due to suicides being incorrectly recorded or misclassified by the coroner as accidental death (Hawton et al., 2015; Samaritans, 2017). This raises questions on the reliability and validity of suicide data, and whether the true prevalence of suicide within existing research is misrepresented.

\subsection{Missing Persons, Suicide and Vulnerability Indicators}

Estimated figures suggest that one in every 100 missing persons in the UK is found dead (Newiss, 2011). However, from 2015 to 2016, 599 missing persons were found dead within England and Wales (UK Missing Persons Bureau, 2017), equating to slightly less than one per cent of all missing persons. Newiss (2011) identified that suicide accounted for the largest proportion of all missing persons found dead, resonating other research findings suggesting suicide to be a considerable cause for fatality in missing persons (Foy, 2016; Sveticic, Too, \& De Leo, 2012; APPG, 2018). Existing research of missing persons who are found dead as a result of suicide has consistently identified men to be at much higher risk of taking their own life than females, with figures indicating between 70 to 80 per cent are male (Foy, 2016; Biehal Mitchell, \& Wade, 2003; Newiss, 2011). This corroborates general suicide research findings confirming that men are more likely to complete suicide than women are (ONS, 2017; WHO, 2014; Hawton et al., 2015; Darke et

\footnotetext{
${ }^{2}$ APP is developed and owned by the College of Policing (the professional body for policing). APP is authorised by the College of Policing as the official source of professional practice on policing.
} 
al., 2010), with the majority being adults (Newiss, 2011; UK Missing Persons Bureau, 2017; Foy, 2016; Biehal et al., 2003). This is in distinct comparison to missing persons found dead to homicide, which often encompasses children (Newiss, 2004).

Some research studies have considered whether the presence of different vulnerabilities or characteristics may be indicative of an individual going missing for the purpose of taking their own life (Newiss, 2011; Sveticic et al., 2012; Foy, 2016; Gibb \& Woolnough, 2007). Gibb and Woolnough (2007) supported that there is a strong link between mental illness and suicide, with a variety of life events acting as a trigger for someone going missing with the intention of taking their own life. In their report, Gibb and Woolnough (2007) highlighted the presence of a suicide note and recent talk of the person talking their own life, as main indicators of a missing person being at risk of suicide.

Moreover, Sveticic et al. (2012) supported the findings by Gibb \& Woolnough (2007) to suggest missing persons at risk of suicide sometimes leave a suicide note. This is also paralleled in other general suicide research, which identified a note to be left in 33 per cent of suicides (Carretta et al., 2015). Further to this, Foy (2016) claimed that a person going missing for the intention of suicide would be expected to display behaviour explicitly or implicitly giving an indication of this decision. Principles relating to behavioural consistency (Canter \& Youngs, 2009) assist in understanding how past behaviour may be reflective of future behaviour, and therefore how previous suicide attempts could indicate further intentions of suicide. Findings by Gibb and Woolnough (2007) echo this notion, suggesting the risk of suicide is higher when the individual has previously attempted it. Canter and Youngs (2009) also emphasised the importance of opportunities and circumstances, which takes into account any obstacles or hindrances to completing suicide. Consequently, access to the right location, together with any required items for suicide, are considered to be two entwined aspects that will be necessary for someone ending their own life (Gibb \& Woolnough, 2007). 
In a separate study by Biehal et al. (2003), it was identified that previous attempts of suicide or intimations of suicide were also discovered as vulnerability factors specific to suicidal missing persons. Newiss (2011) ascertained a number of other significant vulnerability and behaviour indicators to missing person fatalities, including depression, a lack of preparation to leave, problems with substance abuse and also physical health concerns. Moreover, the findings showed that 90 per cent of the missing person cases reported to the police had evidence of at least one vulnerability, with over a third of cases having information relating to four or more vulnerabilities.

On the other hand, Foy (2016) identified that going missing was deemed out of character for over 80 per cent of a 'suicide' subset group of missing persons examined. This finding is supported by Gibb \& Woolnough (2007) who suggested suicide risk is higher if the person has never been reported missing before. Foy (2016) also emphasised the importance of the information given by the individual reporting a suicidal missing person, highlighting that over three-quarters of reporting individuals to correctly suspect the missing person had disappeared with the intention to complete suicide. This demonstrates the value of listening to and acting upon information provided by the reporting individual, as well as the need to address a number of vulnerability concerns at the time the missing person is reported; reflected in findings from a recent All-Party Parliamentary Group (APPG) inquiry (APPG, 2018).

Research to date provides a good insight into vulnerability indicators relevant to missing persons who are found dead due to suicide. The work of Newiss (2011) comprehensively considers a range of vulnerability factors, however it is not known which of these factors are specifically applicable to suicide, given the research considered missing person fatalities in general.

\subsection{Missing Person Investigations - Risk Assessment}

APP guidelines state that safeguarding vulnerable individuals and protecting persons at risk of any harm is a principle key factor for any missing person investigation (College of Policing, 2016). One such safeguarding initiative is the TextSafe ${ }^{\circledR}$ service by the charity Missing People 
where 'a supportive message can be sent to a missing person's phone so they can reach the charity Missing People for free and confidential support' (Missing People, 2016, p.1). This service provides support for vulnerable missing persons who may not wish to contact police but seek assistance or wish to communicate with an impartial third party (Missing People, 2016). Within APP guidance under the responsibilities of the first officer attending a missing person report, a TextSafe ${ }^{\circledR}$ should be arranged by the officer once they have obtained the person's phone number and established whether they have it on them (College of Policing, 2016). Between 2015 and 2016, 14,568 TextSafe ${ }^{\circledR}$ messages were sent to missing persons believed to be within the UK, with the number of TextSafe's requested by police dramatically increasing year on year since 2013 (UK Missing Persons Bureau, 2017).

Within England and Wales, the risk assessment grading applied to any missing persons investigation is important, as it is used to inform and determine the police response assigned, and the required level of resources (College of Policing, 2016). High risk grading is considered when 'the risk of serious harm to the person or public is assessed as very likely' (College of Policing, 2016), with serious harm encompassing life threatening situations. APP guidelines emphasise the critical role of the call handler, given they are usually the first point of contact, and the information they obtain will be used directly within the initial risk assessment grading. APP guidelines outline a number of initial suggested questions for police call handlers to ask, as well as advising that they gather as much relevant information as possible (College of Policing, 2016). Smith and ShalevGreene (2015) stressed the importance of correctly determining the level of risk of a missing person as early on as possible, in order to enable an effective conclusion to the investigation. Nonetheless, Foy (2016) noted a deficiency of structured guidelines provided to police for detecting potential harm to a missing person. This in part is due to a lack of research in this area, which is corroborated in the recent APPG inquiry report findings (APPG, 2018), and as a result has significant implications for accurately determining risk. 
In addition to the APP guidelines, it is anticipated that each respective police force will have its own policy and guidance documentation relating to missing person investigations. Missing People (2015) propose a fixed question script could be of benefit, whereby answers are scored and used within the risk assessment. Moreover, Bonny et al. (2016) insist that the establishment of a standardised checklist is required in order to effectively address all initial investigative questions, which would include risk and vulnerability factors. It is maintained that a call handler should ask all questions regardless of whether they deem them relevant or not (Bonny et al., 2016), which supports the findings by Foy (2016) that the person reporting is best placed to make judgements about the individual who has gone missing. The APPG inquiry (APPG, 2018) also endorses these recommendations, emphasising that the effectiveness of a risk assessment will, in part, be down to the right questions being asked.

At present, a 'clinical' approach is applied to missing persons investigation risk assessments. This utilises professional expertise and practitioner experience, along with reference and application to the APP risk assessment table, missing persons process chart and the national decision model (College of Policing, 2016). Police officers are routinely required to make their own assessment, determining validity, reliability and relevancy of the information presented, which will often draw on instinct and experience (Fyfe, Stevenson, \& Woolnough, 2015). Research findings by Smith and Shalev-Greene (2015) identified that only 50 per cent of police officers in a supervisory role directly involved in the risk assessment of missing person investigations had read national guidelines or their force policy guidelines on missing persons. Therefore, there is the possibility that a lack of understanding could have the potential for devastating knock-on effects for the investigation.

APP states that for missing persons investigations, the use of a numerical scoring system is not considered the most appropriate risk assessment method (College of Policing, 2016) and acknowledges that risk assessment is a subjective process. However, several researchers (Foy, 2016; Newiss, 2005; Newiss, 2004) advocate the use of a structured professional judgement approach. This 
approach combines practitioner judgement and experience, along with a more structured and robust actuarial risk assessment. Newiss (2005) believes such an approach to risk assessment would maximise predictive accuracy and practicality. Nonetheless, it is also accepted that there are difficulties with employing actuarial methods that are based upon evidence and statistical calculations of probability. This is in part due to a lack of general research on missing persons, but secondly for small risk groups, such as those found dead due to suicide, there are difficulties in successfully applying predictive calculations to low base rate occurrences (Bonny et al., 2016; Newiss, 2004; Tarling \& Burrows, 2004). Despite this, it is strongly recommended (APPG, 2018) that more research is required for adult missing persons, to inform any changes to current missing person guidelines, including the risk assessment procedure.

\subsection{The Present Study}

The limited amount of existing research on missing adults resulting in a fatal outcome suggests suicide is a principal cause of death. Hence, the aim of this study was to build on the research conducted by Newiss (2011) and examine the relationship between suicide and adult missing persons, whilst considering a range of vulnerability indicators and how these impact upon the missing person investigation.

\section{Method}

\subsection{Data}

Data was extracted from one police force within England. The data used specifically related to all adult missing persons found dead due to suicide between $1^{\text {st }}$ April 2014 and $31^{\text {st }}$ March 2018. An adult missing person included anyone over the age of 18 years at the time they were found deceased. In this four-year period, there were 13969 reports of adult missing and absent persons received. The number of missing reports within this period included missing adults who had been reported on more than one occasion (repeat missing adults). Therefore, the number of reports was 
higher than 10900, which corresponded to the number of missing adults during this time. Over the four years, there were 153 deaths of adult missing persons, 97 of which were classified or identified to be suspected suicide. However, four data records were excluded from the study due to a large amount of incomplete data making them unsuitable to analyse, resulting in $n=93$. Of the sample, 71 (76.3\%) were male and $22(23.7 \%)$ female. The age range was from 19 to 88 years old $(M=50.14$ $S D=17.38)$

\subsection{Procedure}

The Community Policing and Case Tracking (COMPACT) system was searched for all missing person deaths in the four-year period and interrogated to identify suspected suicides. COMPACT is the missing persons case management system used by this police force and 21 other police forces in England and Wales. The classification of suicide was taken from the 'found' report held on COMPACT. The found report detailed the deceased status of the missing person, the circumstances surrounding the death, along with classification of the death into one of seven categories, one of which was 'unexplained death - possible suicide'. Within the four-year time frame for this study, there were 87 missing adults found dead categorised as 'unexplained death - possible suicide'.

A search was also done of the other six found dead categories; 'unexplained death', 'other', 'homicide', 'natural causes', 'accident / misadventure' and 'not known'. This was to identify whether any missing adults found dead due to suspected suicide had been incorrectly classified. For a suicide to be incorrectly categorised, there needed to be an indication within the circumstances of death or the free text of the found report on COMPACT by the police officer completing, that there was suspicion or belief the person had completed suicide.

From the other six categories, a further 10 missing adults were identified, suspected of suicide. The classification of suicide was based on the details input on the found report by the completing police officer. It is recognised that the certified record of a missing persons death by the 
coroner may in fact be different to the COMPACT found report. Although, it was not possible to obtain coroner records to confirm the deaths, the suicide figures taken from COMPACT relate to the same figures which also inform the UK Missing Persons Unit annual reports.

In addition to COMPACT, the police force command and control System for Tasking and Operational Resource Management (STORM) was searched and interrogated. Command and control systems are used 'for the recording and management of information relating to calls received by a police control room and the subsequent allocation of police resources' (UK Missing Persons Bureau, 2017, p.8). Details were obtained from STORM pertaining to time and date the person was reported missing in all but one of the data records. In the one record where the reported missing time and date was extracted from COMPACT, this was because it was the police themselves who had reported the person missing. On receipt of a call reporting a missing person, a log is opened on STORM, whereby the call handler records all initial detail taken from the reporting person. In conjunction with STORM, which is used to initially allocate police resources, a missing person record is set up on COMPACT to control the overall management of the missing person investigation. At the start of a missing person report, both systems may run in parallel to effectively manage the investigation and the resources deployed.

Details of the time and date the missing person had been found dead were extracted from the found report on COMPACT. Further details regarding the missing persons age; gender; initial risk assessment level that was applied to the missing person report; the number of previous missing episodes; whether a TextSafe ${ }^{\circledR}$ was sent to the missing persons phone; what time and date any TextSafe ${ }^{\circledR}$ was sent; and suspected method of suicide were also extracted from COMPACT. Fourteen vulnerability indicators were examined against each of the missing persons records used in this study. These vulnerability indicators (see Table 1) were created in relation to previous research on missing persons who had completed suicide, as well as literature on general suicide and associated risk factors. 
Table 1. Vulnerability Indicator Variables

\begin{tabular}{|c|c|}
\hline Vulnerability Indicators & Description \\
\hline Risk of Suicide & $\begin{array}{l}\text { If it was deemed that the missing person was likely to attempt } \\
\text { suicide. }\end{array}$ \\
\hline Previously Attempted Suicide & Any previous attempts of suicide by the missing person. \\
\hline Self-Harmed & Whether the missing person had previously self-harmed. \\
\hline Drink/Drug Issues & $\begin{array}{l}\text { If the missing person was known to have alcohol or drug- } \\
\text { related dependencies or issues. }\end{array}$ \\
\hline Not Prepared to Leave & $\begin{array}{l}\text { There was a lack of preparation to go missing, such as not } \\
\text { taking keys, wallet or phone. }\end{array}$ \\
\hline Suicide Note & $\begin{array}{l}\text { The presence of a suicide note, including both handwritten and } \\
\text { electronic messages. }\end{array}$ \\
\hline Other Indications of Suicide & $\begin{array}{l}\text { Any other indications the missing person was considering } \\
\text { committing suicide, such as researching suicide methods, or } \\
\text { recent talk of wanting to end their life. }\end{array}$ \\
\hline Out of Character & Whether the disappearance was out of character for the person. \\
\hline Mental Health Illness & Any diagnosis of mental health illness or known about issues. \\
\hline Depression & $\begin{array}{l}\text { Any diagnosis of depression or belief the missing person was } \\
\text { depressed. }\end{array}$ \\
\hline Medication & $\begin{array}{l}\text { Whether the missing person was taking prescription } \\
\text { medication. }\end{array}$ \\
\hline Relationship Issues & Problems in a romantic relationship. \\
\hline Event (Significant / Other) & $\begin{array}{l}\text { Significant life events or other impactive life circumstances, } \\
\text { such as the bereavement of a family member, job loss. }\end{array}$ \\
\hline $\begin{array}{l}\text { Under Investigation for a Criminal } \\
\text { Offence }\end{array}$ & $\begin{array}{l}\text { If the missing person was being investigated by the police for } \\
\text { any criminal offence. }\end{array}$ \\
\hline
\end{tabular}

COMPACT and STORM were scrutinised for a presence or absence of the vulnerability indicators. Each vulnerability indicator was only considered to be present if it had been identified and recorded by the call handler via the reporting person at the time the missing person report was made. If a vulnerability not necessarily known or disclosed by the reporting person, but was identified by the call handler through immediate intelligence checks or other enquiries and recorded on COMPACT or STORM, it was also counted for the purpose of this study. The rationale of considering only those vulnerabilities identified at the time of the missing report was to establish what impact these had on the initial risk assessment. The suicide note vulnerability indicator referred to traditional written suicide notes, but also encompassed electronic messages to account for modern communication methods. 
Suicide and Associated Vulnerability Indicators in Adult Missing Persons

If there was no documentation of a particular vulnerability indicator, it was assumed not to be present or known about at the time of the missing person report, therefore, was regarded as absent. A dichotomous application for the presence or absence of these vulnerability indicators was considered the most appropriate recording method (Canter \& Fritzon, 1998).

\section{Results}

Cross-tabulations relating to age group and gender (see Table 2) shows which of these groups was most likely to have gone missing and subsequently completed suicide within the four-year time period. Males aged between 50-69 years of age were most prevalent, accounting for $34.4 \%$ of the total missing persons who had completed suicide, followed by males aged 30-49 years of age, who made up $21.5 \%$ of the overall total. Numbers of females found dead due to suicide was similar across all four of the age groups.

Table 2. Age Category and Sex of Missing Adults found Dead due to Suspected Suicide

\begin{tabular}{lllll}
\hline & & \multicolumn{2}{c}{ Sex } & \\
\cline { 3 - 4 } & & Male & Female & Total (\% of Total) \\
\hline $\begin{array}{l}\text { Age Category } \\
\text { (\% of group, \% of }\end{array}$ & $18-29$ & 12 & 5 & 17 \\
total) & $30-49$ & $(70.6 \%, 12.9 \%)$ & $(29.4 \%, 5.4 \%)$ & $(18.3 \%)$ \\
& & 20 & 6 & 26 \\
& $50-69$ & $(76.9 \%, 21.5 \%)$ & $(23.1 \%, 6.5 \%)$ & $(28 \%)$ \\
& & 32 & 5 & 37 \\
& $70+$ & $(86.5 \%, 34.4 \%)$ & $(13.50 \%, 5.4 \%)$ & $(39.8 \%)$ \\
& & $(53.8 \%, 7.5 \%)$ & 6 & 13 \\
& & $716.20 \%, 6.5 \%)$ & $(14 \%)$ \\
\hline Total (\% of Total) & & $(76.3 \%)$ & 22 & 93 \\
& & & $(23.7 \%)$ & $(100 \%)$ \\
\hline
\end{tabular}

The time between a person going missing and the time when they were reported missing to the police ranged between 0 minutes up to 58 days 4 hours 34 minutes $(M=2$ days 11 hours 2 minutes, $M d n=13$ hours 32 minutes, $S D=8$ days 1 hour 32 minutes). Two significant outliers were observed, where the time taken to report the person missing was in excess of 50 days, thereby explaining the disparity between the measures of central tendency. The duration that the person was missing, between being reported to the police and being found dead ranged from 1 minute up to 80 
Suicide and Associated Vulnerability Indicators in Adult Missing Persons

days 17 hours 40 minutes $(M=3$ days 18 hours 40 minutes, $M d n=10$ hours 25 minutes, $S D=11$ days 2 hours 38 minutes). A large proportion of these persons, $62(66.7 \%)$ were found relatively quickly, within one day, but $31(33.3 \%)$ took more than a day to find. In addition, for the $9.7 \%$ of persons who were missing over a week, seven of these nine persons had drowned. In terms of the number of times the person had previously been reported missing at any time prior to the current report, $76(81.7 \%)$ had never gone missing before this incident, $12(12.9 \%)$ had previously gone missing once, three $(3.2 \%)$ had gone missing on two previous occasions, one (1.1\%) had gone missing previously six times, one $(1.1 \%)$ had gone missing on 16 previous occasions. In relation to the suspected method of suicide, this was identified in $87(93.5 \%)$ cases, with six $(6.5 \%)$ cases where the method of suicide was not known. Table 3 shows the method of suicide by sex and age group.

Table 3. Method of Suicide in Relation to Variables of Sex and Age Category

\begin{tabular}{|c|c|c|c|c|c|c|c|c|c|c|c|}
\hline \multicolumn{12}{|c|}{ Method } \\
\hline & & $\begin{array}{l}\text { Carbon } \\
\text { Monoxide }\end{array}$ & Drowned & Firearm & Hanged & $\begin{array}{l}\text { Jumped } \\
\text { off } \\
\text { Cliff }\end{array}$ & $\begin{array}{l}\text { Not } \\
\text { Know }\end{array}$ & $\begin{array}{l}\text { Self- } \\
\text { Inflicted } \\
\text { Stabbing }\end{array}$ & $\begin{array}{l}\text { Self- } \\
\text { Poisoned }\end{array}$ & Train & Total \\
\hline \multirow{2}{*}{$\begin{array}{l}\text { Sex } \\
\text { (\% of } \\
\text { group) }\end{array}$} & Male & $\begin{array}{l}3 \\
(4.2 \%)\end{array}$ & $\begin{array}{l}17 \\
(23.9 \%)\end{array}$ & $\begin{array}{l}3 \\
(4.2 \%)\end{array}$ & $\begin{array}{l}26 \\
(36.6 \%)\end{array}$ & $\begin{array}{l}8 \\
(11.3 \%)\end{array}$ & $\begin{array}{l}6 \\
(8.5 \%)\end{array}$ & $\begin{array}{l}1 \\
(1.4 \%)\end{array}$ & $\begin{array}{l}4 \\
(5.6 \%)\end{array}$ & $\begin{array}{l}3 \\
(4.2 \%)\end{array}$ & $\begin{array}{l}71 \\
(100 \%)\end{array}$ \\
\hline & Female & $\begin{array}{l}0 \\
(0 \%)\end{array}$ & $\begin{array}{l}9 \\
(40.9 \%)\end{array}$ & $\begin{array}{l}0 \\
(0 \%)\end{array}$ & $\begin{array}{l}4 \\
(18.2 \%)\end{array}$ & $\begin{array}{l}6 \\
(27.3 \%)\end{array}$ & $\begin{array}{l}0 \\
(0 \%)\end{array}$ & $\begin{array}{l}0 \\
(0 \%)\end{array}$ & $\begin{array}{l}3 \\
(13.6 \%)\end{array}$ & $\begin{array}{l}0 \\
(0 \%)\end{array}$ & $\begin{array}{l}22 \\
(100 \%)\end{array}$ \\
\hline Total & & $\begin{array}{l}3 \\
(3.2 \%) \\
\end{array}$ & $\begin{array}{l}26 \\
(28 \%) \\
\end{array}$ & $\begin{array}{l}3 \\
(3.2 \%) \\
\end{array}$ & $\begin{array}{l}30 \\
(32.3 \%) \\
\end{array}$ & $\begin{array}{l}14 \\
(15.1 \%)\end{array}$ & $\begin{array}{l}6 \\
(6.5 \%) \\
\end{array}$ & $\begin{array}{l}1 \\
(1.1 \%)\end{array}$ & $\begin{array}{l}7 \\
(7.5 \%)\end{array}$ & $\begin{array}{l}3 \\
(3.2 \%) \\
\end{array}$ & $\begin{array}{l}93 \\
(100 \%)\end{array}$ \\
\hline \multirow{4}{*}{$\begin{array}{l}\text { Age } \\
\text { Category } \\
\text { (\% of } \\
\text { group) }\end{array}$} & $18-29$ & $\begin{array}{l}0 \\
(0 \%)\end{array}$ & $\begin{array}{l}4 \\
(23.5 \%)\end{array}$ & $\begin{array}{l}1 \\
(5.9 \%)\end{array}$ & $\begin{array}{l}7 \\
(41.2 \%)\end{array}$ & $\begin{array}{l}2 \\
(11.8 \%)\end{array}$ & $\begin{array}{l}1 \\
(5.9 \%)\end{array}$ & $\begin{array}{l}0 \\
(0 \%)\end{array}$ & $\begin{array}{l}1 \\
(5.9 \%)\end{array}$ & $\begin{array}{l}1 \\
(5.9 \%)\end{array}$ & $\begin{array}{l}17 \\
(100 \%)\end{array}$ \\
\hline & $30-49$ & $\begin{array}{l}1 \\
(3.8 \%)\end{array}$ & $\begin{array}{l}5 \\
(19.2 \%)\end{array}$ & $\begin{array}{l}0 \\
(0 \%)\end{array}$ & $\begin{array}{l}7 \\
(26.9 \%)\end{array}$ & $\begin{array}{l}5 \\
(19.2 \%)\end{array}$ & $\begin{array}{l}2 \\
(7.7 \%)\end{array}$ & $\begin{array}{l}0 \\
(0 \%)\end{array}$ & $\begin{array}{l}4 \\
(15.4 \%)\end{array}$ & $\begin{array}{l}2 \\
(7.7 \%)\end{array}$ & $\begin{array}{l}26 \\
(100 \%)\end{array}$ \\
\hline & $50-69$ & $\begin{array}{l}1 \\
(2.7 \%)\end{array}$ & $\begin{array}{l}8 \\
(21.6 \%)\end{array}$ & $\begin{array}{l}2 \\
(5.4 \%)\end{array}$ & $\begin{array}{l}16 \\
(43.2 \%)\end{array}$ & $\begin{array}{l}5 \\
(13.5 \%)\end{array}$ & $\begin{array}{l}3 \\
(8.1 \%)\end{array}$ & $\begin{array}{l}1 \\
(2.7 \%)\end{array}$ & $\begin{array}{l}1 \\
(2.7 \%)\end{array}$ & $\begin{array}{l}0 \\
(0 \%)\end{array}$ & $\begin{array}{l}37 \\
(100 \%)\end{array}$ \\
\hline & $70+$ & $\begin{array}{l}1 \\
(7.7 \%)\end{array}$ & $\begin{array}{l}9 \\
(69.2 \%)\end{array}$ & $\begin{array}{l}0 \\
(0 \%)\end{array}$ & $\begin{array}{l}0 \\
(0 \%)\end{array}$ & $\begin{array}{l}2 \\
(15.4 \%)\end{array}$ & $\begin{array}{l}0 \\
(0 \%)\end{array}$ & $\begin{array}{l}0 \\
(0 \%)\end{array}$ & $\begin{array}{l}1 \\
(7.7 \%)\end{array}$ & $\begin{array}{l}0 \\
(0 \%)\end{array}$ & $\begin{array}{l}13 \\
(100 \%)\end{array}$ \\
\hline Total & & $\begin{array}{l}3 \\
(3.2 \%)\end{array}$ & $\begin{array}{l}26 \\
(28 \%)\end{array}$ & $\begin{array}{l}3 \\
(3.2 \%)\end{array}$ & $\begin{array}{l}30 \\
(32.3 \%)\end{array}$ & $\begin{array}{l}14 \\
(15.1 \%)\end{array}$ & $\begin{array}{l}6 \\
(6.5 \%)\end{array}$ & $\begin{array}{l}1 \\
(1.1 \%)\end{array}$ & $\begin{array}{l}7 \\
(7.5 \%)\end{array}$ & $\begin{array}{l}3 \\
(3.2 \%)\end{array}$ & $\begin{array}{l}93 \\
(100 \%)\end{array}$ \\
\hline
\end{tabular}

There were $26(36.6 \%)$ males who were found hanged, contrasted with only four (18.2\%) females. However, there was a higher percentage of females that drowned (40.9\%) compared to males $(23.9 \%)$. Females similarly were more likely to jump off a cliff (27.3\%) or self-poison 
(13.6\%) than males (11.3\% and 5.6\% respectively). In terms of age groups, suicide by hanging was the most prevalent method in three of the age groups; $18-29,30-49$ and 50-69. None of the $70+$ age group used the method of hanging. In this particular age group, drowning was the predominant method (69.2\%) followed by jumping off a cliff (15.4\%).

Regarding the initial risk assessment grading that was applied to the missing person investigation, $3(3.2 \%)$ were graded absent and 2 (2.2\%) were graded low risk, with 43 (46.2\%) graded medium risk and 45 (48.4\%) graded high risk. TextSafe's were sent to $20(21.5 \%)$ of the sample. For those persons who were sent a TextSafe ${ }^{\circledR}$, the time between the person being reported missing to the police and being sent the TextSafe ${ }^{\circledR}$ ranged from 16 minutes up to 3 hours 52 minutes $(M=1$ hour, $S D=48$ minutes $)$.

The presence or absence of fourteen vulnerability indicators was examined for each missing person case in the sample. The total number of vulnerabilities for each missing person ranged from one vulnerability, up to nine vulnerability indicators. The presence of six vulnerability indicators was most prevalent, with 23 (24.7\%) of the sample falling within this group, followed by $17(18.3 \%)$ of the sample presenting four vulnerability indicators, and $15(16.1 \%)$ of the sample presenting five vulnerability indicators. Overall, $77(82.8 \%)$ of the sample presented four or more vulnerability indicators. Frequencies of each of the 14 vulnerabilities are presented in Table 4.

Table 4. Frequency and Percentages of each Vulnerability Indicator

\begin{tabular}{llll}
\hline & & \multicolumn{1}{c}{ Presence of Indicator } \\
\cline { 3 - 3 } Vulnerability & Risk of Suicide & Yes (\% of group) & No (\% of group) \\
Indicator & Previously Attempted Suicide & 29 & 31 \\
& & $(66.7 \%)$ & $(33.3 \%)$ \\
& Self-Harmed & $(31.2 \%)$ & $(68.8 \%)$ \\
& 18 & 75 \\
Drink/Drug Issues & $(19.4 \%)$ & $(80.6 \%)$ \\
& 24 & 69 \\
& Not Prepared to Leave & $(25.8 \%)$ & $(74.2 \%)$ \\
& 26 & 67 \\
& Suicide Note & $(28 \%)$ & $(72 \%)$
\end{tabular}


Suicide and Associated Vulnerability Indicators in Adult Missing Persons

\begin{tabular}{lll} 
& $(18.3 \%)$ & $(81.7 \%)$ \\
Other Indications of Suicide & 39 & 54 \\
& $(41.9 \%)$ & $(58.1 \%)$ \\
Out of Character & 84 & 9 \\
& $(90.3 \%)$ & $(9.7 \%)$ \\
Mental Health Illness & 28 & 65 \\
& $(30.1 \%)$ & $(69.9 \%)$ \\
Depression & 45 & 48 \\
& $(48.4 \%)$ & $(51.6 \%)$ \\
Medication & 50 & 43 \\
& $(53.8 \%)$ & $(46.2 \%)$ \\
Relationship Issues & 18 & 75 \\
& $(19.4 \%)$ & $(80.6 \%)$ \\
Event (Significant / Other) & 40 & 53 \\
& $(43 \%)$ & $(57 \%)$ \\
Under Investigation for a & 10 & 83 \\
Criminal Offence & $(10.8 \%)$ & $(89.2 \%)$ \\
\hline
\end{tabular}

A series of Chi-square and Fisher's exact test analyses were conducted upon the presence or absence of each vulnerability indicator to determine whether there were significant differences relative to gender and also to age group. Fisher's exact was conducted in all instances where over $20 \%$ of the expected frequency cells fell below 5, adhering to Cochran's rule (cited in Coolican, 2014, p.503). Regarding previous attempts of suicide, gender was a significant predictor, with females significantly more likely to have previously attempted suicide than males; $\chi^{2}(1, \mathrm{n}=93)=$ $7.33, p=.007$. Equally, in relation to whether the missing person displayed a lack of preparation to go missing, females compared with males were significantly more likely to display a lack of preparation to go missing; $\chi^{2}(1, \mathrm{n}=93)=6.95, p=.008$.

When examining the presence of a suicide note, males were more likely to leave a suicide note $(\mathrm{n}=16,22.5 \%)$ than females $(\mathrm{n}=1,4.5 \%)$. Whilst this was not statistically significant, the difference approached significance; $\chi^{2}(1, \mathrm{n}=93)=3.64, p=.064$. All other analyses between gender and the vulnerability indicators were not significant. In terms of age, there were no significant differences observed between any of the age categories upon the fourteen vulnerability indicators.

To consider whether differences existed between the initial risk assessment level and presence or absence of each of the vulnerability indicators, separate Mann Whitney U Tests were conducted. A significant difference was identified between the presence of suicide risk, to an 
absence of suicide risk, upon the initial risk assessment level, $U=527.50(\mathrm{Z}=-4.09), p<.001$. The difference between the presence and absence of suicide risk was medium $(r=-.42)$. Additionally, a significant difference was observed between the presence of a suicide note compared to the absence of a suicide note, upon the risk assessment level, $U=370.00(\mathrm{Z}=-3.09), p=.002$, the effect size was medium $(r=-.32)$. There were no other significant differences identified between the other 12 vulnerability indicators upon risk assessment level.

A cumulative odds ordinal logistic regression with proportional odds was then conducted to determine the effect of nine vulnerability indicators on the initial risk assessment level. It was not considered possible to calculate all 14 vulnerability indicators due to the sample size of 93 and risks of extremely low power. Consequently, seven of the vulnerabilities were reduced to three groups; 1 . Previously attempted suicide and self-harm, 2. Mental health illness and depression, 3. Relationship issues, event (significant/other) and under investigation for a criminal offence. The rationale for creating three groups was due to similarities between the vulnerabilities within each group. For each of the new groups, a presence was counted if there was an occurrence of one or more of the vulnerabilities, and absent if there was no occurrence of any of the vulnerabilities. In relation to the vulnerability of medication, although there was a high prevalence within the sample, it was considered that modification of this vulnerability was needed to be of benefit and any meaning to the risk assessment. For this reason, it was discounted from this particular analysis. herefore, the analysis was conducted on the following nine variables; attempted suicide/self-harm, drink/drugs, not prepared to leave, suicide note, other indications of suicide, out of character, mental health illness/depression, and relationship issues/significant/other event/criminal investigation.

Checks confirmed there were no multicollinearity issues between the independent variables. There were proportional odds, as assessed by a full likelihood ratio test comparing the fitted model to a model with varying location parameters, $\chi^{2}(18)=23.01, p=.190$. The deviance and Pearson goodness-of-fit tests indicated that the model was a good fit to the observed data, $\chi^{2}(174)=100.74, p$ 
Suicide and Associated Vulnerability Indicators in Adult Missing Persons

$=1.00$ and $\chi^{2}(174)=171.81, p=.533$ respectively. However, most cells were sparse with zero frequencies in $69.8 \%$ of cells. Nevertheless, the final model significantly predicted the dependent variable over and above the intercept-only model, $\chi^{2}(9)=28.76, p=.001$. Information for the risk assessment level logistic regression model is displayed in Table 5.

Table 5. Ordinal Logistic Regression Model Information for Nine Vulnerability Indicators

\begin{tabular}{lcccc}
\hline Vulnerability Predictors & Wald Statistic & $p$ & $B$ & $95 \%$ CI \\
\hline Risk of Suicide & 9.45 & .002 & 7.53 & $2.08,27.26$ \\
Previously Attempted Suicide / Self-Harmed & 0.13 & .723 & 1.22 & $0.41,3.62$ \\
Drink/Drugs Issues & 0.44 & .506 & 1.45 & $0.48,4.36$ \\
Not Prepared to Leave & 0.11 & .744 & 1.19 & $0.42,3.34$ \\
Suicide Note & 4.49 & .034 & 0.20 & $0.04,0.89$ \\
Out of Character & 0.85 & .357 & 2.11 & $0.43,10.30$ \\
Mental Health Issues / Depression & 1.54 & .215 & 1.88 & $0.69,5.08$ \\
Other Indications of Suicide & 0.01 & .943 & 1.04 & $0.35,3.07$ \\
Relationship Issues/Event (Significant/Other) & 0.49 & .485 & 0.70 & $0.26,1.88$ \\
/Criminal Investigation & & & & \\
\hline
\end{tabular}

Note. Degrees of freedom for all $\chi^{2}=1$.

The only two significant predictors based on Wald's statistic were a risk of suicide and the presence of a suicide note. The odds of a risk of suicide linking to a higher risk level was 7.53 (95\% CI, 2.08 to 27.26) times that of no suicide risk; a statistically significant effect $\chi^{2}(1)=9.45, p=.002$. The odds of a suicide note linking to a higher risk level was 0.20 (95\% CI, 0.04 to 0.89 ) times that of no suicide note; a statistically significant effect $\chi^{2}(1)=4.49, p=.034$.

\section{Discussion}

This study aimed to examine the relationship between adult missing persons and suicide. Through an examination of data relating to missing persons who had been found dead due to suspected suicide, and a variety of factors that have been considered, this study has increased the 
understanding between missing persons and suicide. The results identified that a significant proportion of these persons are male, consistent with previous research in this area (Foy, 2016;

Biehal et al., 2003; Newiss, 2011). Furthermore, the majority of these males were aged between 30 and 69 years of age. The number of females observed was much smaller, with similar numbers of females seen within each of the four age categories considered. For the majority of the sample, this was their first missing episode, with a small proportion of persons that had been missing before on one or more occasions.

Over half of the sample were found dead within 12 hours of being reported missing, substantiating the findings of Newiss (2011) that those taking their own life generally do so relatively quickly after going missing. In nine cases, it took more than one-week to locate the missing person, with seven of these nine cases involving circumstances where the person had drowned. The time delay of finding a person who has drowned can be as a result of tidal effects and river flows, whereby the body can travel significant distances from the point of entry into water (Gibb \& Woolnough, 2007). There were interesting findings regarding the method of suicide in relation to age and gender variables, with double the proportion of males to females choosing hanging. In contrast, higher percentages of females chose to drown, jump off a cliff or self-poison. Moreover, hanging was the most common suicide method presented in three of the four age groups, with no hangings observed within the 70+ age category. Instead, drowning followed by jumping off a cliff were the predominant methods of suicide by persons aged $70+$. This could generally be due to persons of this age not having the physical strength or ability to consider hanging, and therefore opting for more accessible methods of suicide, although this finding is not corroborated in other research (Shah \& Buckley, 2011).

Exploration of the 14 vulnerabilities identified a number of these indicators to be prevalent to missing persons who had completed suicide. The disappearance being out of character was the most common vulnerability, corresponding to the fact that most persons who go missing and take their 
own life have never been reported missing previously. Other frequent vulnerabilities included, the risk of suicide, other indications of suicide, depression, taking medication and the occurrence of a significant event. Analyses of the vulnerability indicators with respect to gender and age group revealed some significant differences. Compared to males, females were significantly more likely to have previously attempted suicide, and also demonstrated a lack of preparation to go missing. Males, on the other hand, were more likely than females to leave a suicide note, although this was not statistically significant. None of the analyses between the age groups and vulnerability indicators presented significant differences, signifying that all vulnerabilities run across the span of adulthood.

In relation to risk assessment levels, the majority of missing persons were graded medium or high risk, with five cases where the initial risk grading was absent or low. From a series of Mann Whitney U tests, to consider differences on the risk assessment grading in relation to the presence or absence of each vulnerability indicator, significant differences were only identified in relation to the presence of a suicide risk, and separately the presence of a suicide note upon the risk assessment. The effect of nine vulnerability indicators were then considered upon the risk assessment grading, with the risk of suicide, and the presence of a suicide note being the only predictors of higher risk assessment gradings. None of the other vulnerability indicators produced a statistically significant predictive effect upon the risk assessment level.

\subsection{Missing Persons, Suicide and Vulnerability Indicators}

The data revealed that over the four years, 60 per cent missing person disappearances resulting in death were due to suspected suicide. This supports previous research by Newiss (2011) who also identified suicide to be the largest single known cause of death in missing persons. Consistent with Gibb and Woolnough (2007), this study identified that the majority of suicides had never been reported missing previously. Uncoincidentally, a persons disappearance was out of character in over 90 per cent of this sample, resonating similar findings by Foy (2016), and providing justification to support the fact the majority had not been reported missing before, providing support 
that a missing occurance would be out of character. Together, these findings show how the risk of suicide should not be ignored within the initial risk assessment process when coupled with other vulnerabilities or likelihood the missing person is going to come to serious harm. The use of TextSafe ${ }^{\circledR}$ as a safeguarding service was also explored, with records suggesting one-fifth of the sample were sent a TextSafe ${ }^{\circledR}$. Whilst this figure appears low, it is recognised that the facility of an automated TextSafe ${ }^{\circledR}$ via COMPACT was only introduced by this police force in early 2016 . Of note was the time taken to initiate a TextSafe ${ }$, which ranged from minutes to several hours. Coupled with the finding that persons who go missing with the intention of ending their life are likely to complete suicide relatively quickly (Newiss, 2011), it is questioned whether a TextSafe® could be sent more rapidly as a potential lifesaving intervention.

Substantiating previous research of suicide in general (Hawton et al. 2013), and fatal outcomes in missing persons (Newiss, 2011), this study identified nearly half of the sample to have manifestations of depression, whether this be a medical diagnosis for depression, or the reporting person having serious concerns that the missing person was depressed. Correspondingly, although not quite as frequent as depression, just under a third of the sample suffered from a mental health illness of some description other than depression. These figures combined (78.5\%) show the prevalence of mental health illnesses, particularly depression, in suicidal individuals, and a requirement to explore these issues when suicide is highlighted as a concern for a missing person. Various research has also drawn attention to the impact of a life event on suicide (Bagge et al.,2013; Cooper et al., 2002; Cavanagh et al., 1999), with a range of negative life events considered. This study considered three broad areas of 'life events', including being under investigation for a criminal offence, problems in a romantic relationship, and significant/other events. Significant/other events included, for example, the recent death of a loved one, the anniversary of a loved one's death or health-related issues relating to the missing person. Although the frequencies of relationship issues and those under criminal investigation were much lower than significant/other events, when 
combined and totalled, it shows approximately three-quarters of the sample had been experiencing some sort of negative life event. This demonstrates that the presence of a negative life event pertinent to the missing person, regardless of what the event may be, needs to be appreciated and taken into consideration, particularly when there is the co-occurrence of other vulnerability indicators.

Interestingly, for over 40 per cent of the sample, particulars relating to other indications of suicide were recorded by the initial call handler opening the missing person log. Such indications included the reporting person being aware that the missing person had recently researched suicide methods, the missing person talking of wanting to end their life/not being able to continue with life, or the person apologising and verbally saying goodbye to friends and loved ones prior to going missing. These findings again resonate previous research (Foy, 2016; Gibb \& Woolnough, 2007; Biehal et al., 2003) suggesting that a person going missing with the purpose of suicide will display behaviour implicitly or explicitly giving an indication of their intentions. This also validates the importance of listening to the reporting persons concerns, something which is highlighted by Foy (2016) but also advocated within the recent APPG inquiry (APPG, 2018). The initial call handler may ascertain details relating to a life event, or to other indications of suicide through the APP suggested question 'Is there any other information relevant to their absence?' (College of Policing, 2016). Nonetheless, it is not known to what extent this question is adopted by all England and Wales police forces, therefore, opportunities to identify harm and appropriately assess risk might be missed, which could result in life-threatening outcomes.

Other vulnerability indicators explored were present within the sample to various extents. The occurrence of a previous suicide attempt or self-harm were 31 per cent and 19 per cent repectively, concurring with the findings by Newiss (2011) and general suicide research (Borges et al., 2010; Bergen et al., 2012; Hawton et al., 2015; Runeson et al., 2010). It is questioned however, what distinguishes a previous suicide attempt and self-harm, with existing literature presenting previous suicide attempts and self-harm differently. For instance, Bergen et al. (2012) references 
previous attempts of hanging and self-poisoning as incidents of non-fatal self-harm, whereas Runeson et al. (2010) refers to these episodes as attempted suicide. This emphasises the existence of subjective interpretations and potentially demonstrates a requirement to consider instances of attempted suicide and self-harm with the same degree of concern and risk. When these two vulnerabilities were grouped for the purpose of the ordinal logistic regression, a combined presence or absence of previous attempted suicide and self-harm did not significantly effect the initial risk assessment grading. Akin to Newiss (2011), the presence of medication showed to be a further common vulnerability, with over half of the sample taking prescription medication at the time of their disappearance. Given the prevalence of prescription medication in general for a variety of ailments (HSE, 2013), it is questioned what benefit this information has on its own without further interrogation. Enquiries such as whether the missing person has taken their prescription medication with them, or whether there are quantities of medication missing, are deemed appropriate questions to establish what potential risks associating to the prescription medication there are. As it was considered further refinement of this vulnerability is needed in order to be of value to the risk assessment process, it was excluded from the ordinal logistic regression analysis.

Conversely, a suicide note was only observed in 18 per cent of this study's sample, which is much lower than the 43 per cent ascertained by Sveticic et al. (2012). It must be mentioned that the presence of a suicide note was only considered if it had been found at the point when the person was reported missing. This was in order to establish whether it had an impact upon the initial risk assessment level. The presence of a suicide note and a risk of suicide to the missing person were the only two vulnerabilities present, as opposed to an absence of these variables, to have a significant difference on the risk assessment grading.

These results are interesting, as it shows that the majority of vulnerability indicators, regardless of whether they were present or absent actually had no signficant effect or difference on whether a missing person investigation was initially graded as absent, low, medium or high. Four of 
the five cases asssessed as absent or low risk had a presence of three or four vulnerabilities, with one of the absent cases having the presence of eight vulnerability indicators. It is recognised that the existence of vulnerabilities are not evaluated in isolation and these will be considered in conjunction with a variety of other factors when assessing risk. However, these findings highlight potential shortcomings of the current risk assessment process, demontrating its subjective nature (Foy, 2016; Newiss, 2005; Newiss, 2004). This has the potential to effect initial risk assessment decisions and subsequently the police response, which may have fatal consequences. These findings further corroborate concerns highlighted within the APPG inquiry, which calls for missing person risk assessment processes to be standardised, and for the questions used within the risk assessment to be empirically tested (APPG, 2018).

\subsection{Practical Implications}

The current study identified the prevalence of vulnerabilities in relation to adult missing persons who are suspected of suicide. An understanding of the vulnerabilities pertinent to suicidal missing persons is an important process for properly assessing risk. Nonetheless, this study has demonstrated how most vulnerabilities do not appear to effect or predict the risk assessment level that is initially applied to a missing person investigation. Various research studies have alluded to the subjective nature of a missing person risk assessment (Fyfe et al., 2015; Newiss, 2004; Newiss, 2005) whereby information important to the risk assessment process is is open to interpretation and difference. These findings provide support that the risk assessment process is indeed subjective and that variances occur from one risk assessment to the next. Although the importance of the vulnerabilities explored need to be further established, this study goes some way to espousing a more robust risk assessment that combines actuarial and professional judgement methods. The primary concern for any risk assessment should be to identify the potential for harm, and ensuring the missing person is appropritely safeguarded, with the latter achieved via an effective police reponse. Therefore, it is suggested that the most effectual risk assessment process is not presently achieved. 
In repect to possible safeguarding interventions, the function of TextSafe $®$ is potentially of particular value for missing persons intending suicide. As it is acknowledged that those who complete suicide generally do so relatively soon after going missing, TextSafe ${ }^{\circledR}$ may provide an allimportant lifeline. The results of this study indicate TextSafe's are initiated relatively quickly after receipt of a missing report within minutes or hours. Although APP states that a TextSafe® falls within the responsibilities of the first officer attending (College of Policing, 2016), there might be benefit for the call handler to obtain the missing persons phone number and initiate the TextSafe ${ }^{\circledR}$ without any delay. This may maximise chances of reaching out and providing vital support to that missing person.

Correspondingly, APP (College of Policing, 2016) emphasises the vital role of the call handler receiving the missing persons report, particularly in relation to questions asked in order to establish risk issues and the potential for harm to occur. Although APP provides a number of initial suggested questions (College of Policing, 2016), it is suspected that a number of these questions may not necessarily obtain answers regarding some of the vulnerabilities that have been highlighted in this study. Advocating recommendations within the APPG inquiry (APPG, 2018), this study proposes that the validity and effectiveness of standard risk assessment questions should be considered in conjunction with identifying necessary vulnerabilities. Evidence that supports a set of risk assessment questions may assist with implementing a fixed question script, something which is endorsed by Missing People (2015). Further to effective risk questions, the value of information provided by the reporting person is considered to be central to a missing person investigation (Foy, 2016; APPG, 2018). Owing to a wealth of data captured regarding the different vulnerabilities, the findings from this study support this notion, and that the concerns of the reporting person should be taken seriously when exploring risk. Training and upskilling for call handlers is considered appropriate, to highlight the importance of the information they obtain and the consequences it has to any risk assessment. 


\subsection{Limitations and Directions for Future Research}

It is recognised that the sample size employed was relatively small when considering the number of adults that go missing each year. However, the number of missing persons found dead due to suicide represent only a small proportion of all missing person cases. In conjunction with the small sample, it is also acknowledged that this data was only obtained from one English police force, which may be subject to specific social and geographical variances. This may present difficulties with generalizability; it is possible that different methods are employed in other countries. However, this can be addressed by future research with a broader sample and perhaps a comparison between the UK and other European counties, or between the UK and USA. Additionally, it is accepted that due to the small sample size, it was not possible to analyse all vulnerabilities in respect of their effect upon the risk assessment level.

Moreover, each of the 14 vulnerabilities considered within this study were created and justified in relation to existing research on suicide and suicide in missing persons. Therefore, perhaps the vulnerability indicator of 'medication' was somewhat vague. For this reason, the medication vulnerability was excluded from the ordinal logistic regression even though the prevalence of it was quite high. It is suggested that refinement of this variable would be required for any future research. Furthermore, there was no inter-rater reliability process to ensure consensus regarding the presence or absence of each of the vulnerability indicators. The vulnerabilities were recorded dichotomously, to try and reduce the opportunity for variability and discrepancy.

Given that the present study focused solely upon missing persons who had completed suicide, it would be prudent to assess whether the vulnerability indicators explored are indeed unique to this group of missing persons, or whether their presence is prevalent among a wider group of missing persons who do not go missing with the intention of suicide. In conjunction with this, future research may consider further refining the vulnerability indicators, that may consider some vulnerabilities more broadly, or whether there are others that need to be more specific. This is an important piece of 
research that would need to be conducted in order to understand what vulnerability indicators are specific to missing persons with suicidal intentions as opposed to missing persons in general.

Concerns regarding the current risk assessment process have also been highlighted throughout this study and have supported findings from previous research (Foy, 2016; Newiss, 2005; Newiss, 2004). It is encouraged that future research examines current risk assessment processes; its capabilities to effectively identify vulnerabilities and harm, but in addition how these impact upon the risk assessment grading. Queries regarding the APP initial suggested questions (College of Policing, 2016) have been raised, including whether these questions are adopted and used consistently by police forces in England and Wales, or if there are variations implemented by individual police forces. In addition, the findings from this study have challenged whether these suggested questions have the ability to comprehensively identify harm, vulnerability and therefore risk. Future research should consider the effectiveness of initial risk assessment questions, what variations occur between police forces in England and Wales, but additionally the impact of this. As the presence of a suicide note was identified as a risk indicator, it would be worth exploring the suicide notes further to identify the main themes identified in these notes and to examine differences or similarities with suicide notes left by individuals who complete suicide but don’t go missing (see Ioannou \& Debowska, 2014; Synnott, Ioannou, Coyne, Hemingway, 2017).

Lastly, it would be worth exploring the psychological narratives of missing persons in order to understand underlying emotions and roles that may contribute to the decision to go missing. A number of studies have shown the importance of narratives with offenders (Ioannou, 2006; Ioannou, Canter, Youngs \& Synnott, 2015; Ioannou, Canter \& Youngs, 2017; Ioannou, Synnott, Lowe \& Tzani-Pepelasi, 2018; Yaneva, Ioannou, Hammond \& Synnott, 2018). While behavioural narratives have been explored with missing children (Payne, 1995) and missing adults (Bonny, Almond \& Woolnough, 2016) both explorations are focused on behavioural differentiations as opposed to 
Suicide and Associated Vulnerability Indicators in Adult Missing Persons

psychological exploration which can provide an insight into missing persons' intentions and the decision to go missing.

\section{References}

Association of Chief Police Officers (ACPO). (2013). Interim guidance on the management, recording and investigation of missing persons 2013. London: College of Policing.

Association of Chief Police Officers (ACPO). (2015, March 11). Changes to the definition of "Absent" \& other matters. London.

All Party Parliamentary Group (APPG). (2018). Inquiry into safeguarding missing adults who have mental health issues. London: All Party Parliamentary Group.

Bagge, C. L., Glenn, C. R., \& Lee, H.-J. (2013). Quantifying the impact of recent negative life events on suicide attempts. Journal of Abnormal Psychology, 122, 359-368. DOI: 10.1037/a0030371 
Suicide and Associated Vulnerability Indicators in Adult Missing Persons

Bebbington, P. E., Minot, S., Cooper, C., Dennis, M., Meltzer, H., Jenkins, R., \& Brugha, T. (2010). Suicidal ideation, self-harm and attempted suicide: Results from the British psychiatric morbidity survey 2000. European Psychiatry, 25, 427-431. doi:

10.1016/j.eurpsy.2009.12.004.

Bergen, H., Hawton, K., Waters, K., Ness, J., Cooper, J., Steeg, S., \& Kapur, N. (2012). How do methods of non-fatal self-harm relate to eventual suicide? Journal of Affective Disorders, 136, 526-533. doi: 10.1016/j.jad.2011.10.036.

Biehal, N., Mitchell, F., \& Wade, J. (2003). Lost from view: Missing persons in the UK. Bristol: The Policy Press.

Bonny, E., Almond, L., \& Woolnough, P. (2016). Adult missing persons: Can an investigative framework be generated using behavioural themes? Journal of Investigative Psychology and Offender Profiling, 13, 296-312. DOI: 10.1002/jip.1459.

Borges, G., Nock, M. K., Haro Abad, J. M., Hwang, I., Sampson, N. A., Alonso, J., \& ... Kessler, R. C. (2010). Twelve month prevalence of and risk factors for suicide attempts in the WHO world mental health surveys. The Journal of Clinical Psychiatry, 71, 1617-1628. doi: 10.4088/JCP.08m04967blu.

Canter, D., \& Fritzon, K. (1998). Differentiating arsonists: A model of firesetting actions and characteristics. Legal and Criminological Psychology, 3, 73-96. Retrieved from: https://doiorg.libaccess.hud.ac.uk/10.1111/j.2044-8333.1998.tb00352.x.

Canter, D., \& Youngs, D. (2009). Investigative psychology. Chichester: John Wiley and Sons Ltd.

Carretta, C. M., Burgess, A. W., \& Welner, M. (2015). Gaps in crisis mental health: Suicide and homicide-suicide. Archives of Psychiatric Nursing, 29, 339-345. http://dx.doi.org/10.1016/j.apnu.2015.06.002. 
Suicide and Associated Vulnerability Indicators in Adult Missing Persons

Carroll, R., Thomas, K. H., Bramley, K., Williams, S., Griffin, L., Potokar, J., \& Gunnell, D. (2016). Self-cutting and risk of subsequent suicide. Journal of Affective Disorders, 192, 8-10. doi: 10.1016/j.jad.2015.12.007.

Cavanagh, J. T., Owens, D. G., \& Johnstone, E. C. (1999). Life events in suicide and undetermined death in south-east Scotland: a case-control study using the method of psychological autopsy. Social Psychiatry and Psychiatric Epidemiology, 34, 645-650. Retrieved from: https://doiorg.libaccess.hud.ac.uk/10.1007/s001270050187.

College of Policing. (2016, November 21). Major investigation and public protection - Missing persons. Retrieved from Authorised Professional Practice: https://www.app.college.police.uk/app-content/major-investigation-and-publicprotection/missing-persons/\#the-risk-assessment-table.

College of Policing. (2018, January 26). Detention and custody: Risk assessment. Retrieved from Authorised Professional Practice: https://www.app.college.police.uk/app-content/detentionand-custody-2/risk-assessment/\#risk-of-self-harm-and-suicide-after-release.

Coolican, H. (2014). Research Methods and Statistics in Psychology (Sixth ed.). Hove, East Sussex, United Kingdom: Psychology Press.

Cooper, J., Appleby, L., \& Amos, T. (2002). Life events preceding suicide by young people. Social Psychiatry and Psychiatric Epidemiology, 37, 271-275. doi:10.1007/s001270200019.

Darke, S., Torok, M., Crim, M., Kaye, S., \& Ross, J. (2010). Attempted suicide, self-harm, and violent victimization among regular illicit drug users. Suicide and Life-Threatening Behaviour, 40, 587-596. Retrieved from: https://doi-org.libaccess.hud.ac.uk.

Foy, S. (2016). A profile of missing persons: Some key findings for police officers. In S. J.

Morewitz, \& C. Sturdy Colls, Handbook of missing persons (pp. 7-18). Switzerland: Springer International Publishing. 
Suicide and Associated Vulnerability Indicators in Adult Missing Persons

Fyfe, N. R., Stevenson, O., \& Woolnough, P. (2015). Missing persons: The process and challenges of police investigation. Policing and Society, 25, 409-425. DOI: 10.1080/10439463.2014.881812.

Gibb, G. J., \& Woolnough, P. (2007). Missing persons: Understanding, planning, responding. Aberdeen: Grampian Police.

Harwood, D., Hawton, K., Hope, T., \& Jacoby, R. (2001). Psychiatric disorder and personality factors associated with suicide in older people: A descriptive and case-control study. International Journal of Geriatric Psychiatry, 16, 155-165. Retrieved from: https://doiorg.libaccess.hud.ac.uk.

Hawton, K., Bergen, H., Cooper, J., Turnbull, P., Waters, K., Ness, J., \& Kapur, N. (2015). Suicide following self-harm: Findings from the multicentre study of self-harm in England, 200-2012. Journal of Affective Disorders, 175, 147-151. http://dx.doi.org/10.1016/j.jad.2014.12.062.

Hawton, K., Casanas i Comabella, C., Haw, C., \& Saunders, K. (2013). Risk factors for suicide in individuals with depression: A systematic review. Journal of Affective Disorders, 147, 17-28. http://dx.doi.org/10.1016/j.jad.2013.01.004.

Hoffer, T. A., Shelton, J. L., Behnke, S., \& Erdberg, P. (2010). Exploring the impact of child sex offender suicide. Journal of Family Violence, 25, 777-786. Retrieved from: https://doiorg.libaccess.hud.ac.uk.

Health Survey for England (HSE). (2013). Health survey for England 2013: Health, social care and lifestyles: Summary of key findings. London: Health \& Social Care Information Centre.

Ioannou, M. (2006). Hero or villain? Criminals' experience of crime. ( $\mathrm{PhD}$ thesis). University of Liverpool, Liverpool.

Ioannou, M., Canter, D., \& Youngs, D. (2017). Criminal narrative experience: Relating emotions to offence narrative roles during crime commission. International Journal of Offender Therapy and Comparative Criminology, 61(14), 1531-1553. doi:10.1177/0306624X15625991 
Suicide and Associated Vulnerability Indicators in Adult Missing Persons

Ioannou, M., Canter, D., Youngs, D., \& Synnott, J. (2015). Offenders' Crime Narratives Across Different Types of Crimes. Journal Of Forensic Psychology Practice, 15(5), 383-400.

Ioannou, M. \& Debowska, A. (2014). Genuine and simulated suicide notes: An analysis of content. Forensic Science International, 245, 151-160. doi: 10.1016/j.forsciint. 2014.10.035.

Ioannou, M., Synnott, J., Lowe, E. \& Tzani-Pepelasi, C. (2018). Applying the criminal narrative experience framework to young offenders. International Journal of Offender Therapy and Comparative Criminology, 1-17.

Missing People. (2015, October). Missing people's response to the authorised professional practice consultation on missing persons - October 2015. Retrieved from Missing People: https://www.missingpeople.org.uk.

Missing People. (2016). Request a TextSafe. Retrieved from Missing People: https://www.missingpeople.org.uk/how-we-can-help/professionals/police-services/180request-a-textsafe.html.

Newiss, G. (2004). Estimating the risk faced by missing persons: A study of homicide victims as an example of an outcome-based approach. International Journal of Police Science \& Management, 6, 27-36. Retrieved from: https://doi-org.libaccess.hud.ac.uk.

Newiss, G. (2005). A study of the characteristics of outstanding missing persons: Implications for the development of police risk assessment. Policing and Society, 15, 212-225. DOI: $10.1080 / 10439460500071655$.

Newiss, G. (2006). Understanding the risk of going missing: Estimating the risk of fatal outcomes in cancelled cases. Policing: An International Journal of Police Strategies \& Management, 29, 246-260. https://doi.org/10.1108/13639510610667655.

Newiss, G. (2011). Learning from fatal disappearances. London: Missing People. 
Suicide and Associated Vulnerability Indicators in Adult Missing Persons

Office for National Statistics (ONS). (2017). Suicides in the UK: 2016 registrations. Newport: Office for National Statistics.

Runeson, B., Tidemalm, D., Dahlin, M., Lichtenstein, P., \& Langstrom, N. (2010). Method of attempted suicide as predictor of subsequent successful suicide: national long term cohort study. BMJ, 340, 1-6. doi: 10.1136/bmj.c3222.

Samaritans. (2017). Suicide statistics report 2017. Ewell: Samaritans.

Shah, A., \& Buckley, L. (2011). The current status of methods used by the elderly for suicides in England and Wales. Injury \& Violence, 3, 68-73. doi:10.5249/jivr.v3i2.78.

Shalev Greene, K., \& Pakes, F. (2013). The cost of missing person investigations: Implications for current debate. Policing, 8, 27-34. doi: 10.1093/police/pat36.

Smith, R., \& Shalev-Greene, K. (2015). Recognizing risk: The attitudes of police supervisors to the risk assessment process in missing person investigations. Policing, 9, 352-361. doi: 10.1093/police/pav016.

Stevenson, O., Parr, H., \& Woolnough, P. (2016). Missing women: policing absence. Transactions of the Institute of British Geographers, 42, 220-232. doi: 10.1111/tran.12160.

Sveticic, J., Too, L. S., \& De Leo, D. (2012). Suicides by persons reported as missing prior to death: A retrospective cohort study. BMJ Open, 2, 1-7. doi:10.1136/bmjopen-2011- 000607.

Synnott, J., Ioannou, M., Coyne, A., \& Hemingway, S. (2017). A content analysis of online suicide notes: Attempted suicide versus attempt resulting in suicide. Suicide and LifeThreatening Behavior, 1-12. doi: 10.1111/sltb.12398.

Tarling, R., \& Burrows, J. (2004). The nature and outcome of going missing: the challenge of developing effective risk assessment procedures. International Journal of Police Science \& Management, 6, 16-26. Retrieved from: https://doi-org.libaccess.hud.ac.uk.

Turecki, G., \& Brent, D. A. (2016). Suicide and suicidal behaviour. Lancet, 387, 1227-1239. http://dx.doi.org/10.1016/ S0140-6736(15)00234-2. 
Suicide and Associated Vulnerability Indicators in Adult Missing Persons

UK Missing Persons Bureau. (2017). Missing persons data report 2015/2016. Sunningdale: National Crime Agency.

World Health Organisation (WHO). (2014). Preventing suicide: A global imperative. Luxembourg: World Health Organization.

Yaneva, M., Ioannou, M., Hammond, L., \& Synnott, J. (2018). Differentiating Contract Killers: A Narrative-Based Approach. The Howard Journal of Crime and Justice. DOI: 10.1111/hojo.12243.

Youngs, D. (2013). Investigative psychology: David Canter's approach to studying criminals and criminal action. In D. Youngs, Behavioural analysis of crime. Farnham: Ashgate Publishing Ltd. 